\title{
Umbra e o Caçador de androides: um olhar à luz da ecocrítica e ecofeminismo
}

\author{
Naiara Sales Araújo \\ Universidade Federal do Maranhão \\ São Luís, Brasil \\ Amanda Lima** \\ Universidade Federal do Maranhão \\ São Luís, Brasil \\ Recebido em: 04/04/2019 \\ Aceito em: 17/06/2019
}

Resumo: $O$ presente estudo tem como objetivo analisar as narrativas distópicas Umbra (1977), de Plínio Cabral, e O Caçador de Androides (1968), de Philip K. Dick, à luz dos estudos da Ecocrítica e do Ecofeminismo. A premissa básica do ecofeminismo é de que a ideologia que autoriza opressões, como aquelas baseadas em raça, classe, gênero, sexualidade é a mesma ideologia que sanciona a opressão da natureza (GAARD, 1993). Os resultados apontam para uma importante contribuição da literatura distópica enquanto meio capaz de dialogar com diversas áreas de estudo, de modo a viabilizar tão importantes quanto necessárias reflexões ao meio social.

Palavras-chave: Umbra. O caçador de Androides. Distopia. Ecologia.

Abstract: This study aims to analyze the dystopic narratives Umbra (1977), by Plínio Cabral, and O Caçador de Androides (1968), by Philip K. Dick, in the light of Ecocriticism and Ecofeminism. The basic premise of ecofeminism is that the ideology which authorizes oppressions, such as the ones based on race, class, gender, sexuality, physical abilities, and species, is the same ideology which sanctions the oppression of nature (GAARD, 1993). The results suggest a major contribution of dystopic literature as a way of raising a dialogue with many areas of study, facilitating reflections both important and necessary to the social environment.

Keywords: Umbra. O Caçador de Androides. Dystopia. Ecology.

Resumen: El presente estudio tiene como objetivo analizar las narrativas distópicas Umbra(1977), de Plinio Cabral, y O Caçador de Androides(1968), de Philip K. Dick, a la luz de los estudios de la Ecocritica y del Ecofeminismo. La premisa básica del ecofeminismo es que la ideología que autoriza opresiones, como aquellas basadas en raza, clase, género, sexualidad es la misma ideología que sanciona la opresión de la naturaleza (GAARD, 1993). Los resultados apuntan a una importante contribución de la literatura distópica como medio capaz de dialogar con diversas áreas de estudio, de modo a viabilizar tan importantes como necesarias reflexiones al medio social.

Palabras clave: Umbra. O Caçador de Androides. Distopia. Ecologia. 


\section{Introdução}

Entre tantas outras finalidades, a literatura objetiva refletir sobre situações cotidianas e problemas sociais, tendo em vista que muito do que é posto se remete a costumes que revelam os detalhes da época em que a obra fora escrita.

Considerando essa realidade, as distopias - objeto deste estudo - surgem como subgênero da ficção científica e são apontadas como ferramentas de reflexão social, sobretudo no tocante aos efeitos gerados pelo desenvolvimento tecnológico e sofridos pelo homem enquanto ser social. Frequentemente, autores que lidam com essa temática embasam suas narrativas a partir de observações presentes, considerando os impactos das ações do homem para o futuro.

Partindo desse pressuposto, o presente estudo emana de uma percepção decorrente da leitura das seguintes obras literárias: Umbra (1977), de Plínio Cabral, e $O$ caçador de androides (1968), de Philip K. Dick. Tais narrativas têm notáveis semelhanças e ambas são consideradas distopias, o que propicia o desenvolvimento de várias reflexões a respeito da sociedade em que vivemos. Tanto Umbra quanto $O$ caçador de androides remetem a uma preocupação global: a destruição do meio ambiente. Nesse sentido, a discussão ora proposta optou por fazer uma analogia entre a natureza (mãe terra/mãe natureza) e o ser feminino.

Assim, este estudo tem como principal objetivo analisar as obras Umbra (1977), de Plínio Cabral, uma distopia brasileira, e O caçador de Androides (1968), de Philip K. Dick, distopia americana, com o intuito de constatar a ampla reflexão que essas obras propiciam no tocante à destruição da natureza pela ação do homem, à luz da teoria ecofeminista e da ecocrítica.

\section{Ecocrítica: ecologia, lugar e homem}

Os saberes relacionados à ecocrítica surgiram quando as mudanças no planeta Terra se tornaram visíveis e nocivas à vida humana. Tal constatação fez com que a ecologia ultrapassasse suas fronteiras e se tornasse objeto não só de pesquisas no âmbito das ciências biológicas ou da natureza, mas também das ciências humanas e sociais.

Os estudos nesse âmbito ganharam mais visibilidade a partir dos apontamentos de ambientalistas sociais e dos críticos norte-americanos Cheryll Glotfelty e Harold Fromm, expostos na antologia The Ecocriticism Reader: Landmarks in Literary Ecology (1996). Os autores tratam da relação entre a literatura e o ambiente físico, adotando uma abordagem em estudos literários com enfoque na Terra, na natureza e na relação desta última com o homem.

Cheryll Glotfelty (1996) faz uma breve retomada histórica de como a ecocrítica surgiu e detecta que os estudos literários demoraram bastante a fazer uma teoria que envolvesse literatura e ecologia (havia muitos autores que buscavam essa ligação, porém, de modo isolado). Efetivamente, a ecocrítica alavancou quando surgiram várias conferências e sessões sobre enviromental literature, e uma das mais notáveis ocorreu em 1991, com Harold Fromm, intitulada Ecocriticism: The Greening of Literary Studies. Ou 
seja, esse estudo, ao final do século XX, já havia se tornado uma escola crítica e reconhecida de estudos literários ambientalistas.

Glotfelty (1996) descreve a ecocrítica como o estudo da correlação entre a literatura e o meio ambiente. Em outros termos, essa temática busca uma aproximação entre literatura e natureza, pondo esta última em evidência. Segundo o mesmo autor, a partir dessa aproximação é possível fazer vários questionamentos, como: Qual a importância do meio ambiente para o enredo de uma narrativa? Assim como raça, classe e gênero, o lugar poderia também fazer parte da crítica literária?

Nessa perspectiva, a ecocrítica é uma teoria que dá subsídios para que se analisem textos literários com foco ecológico explorando, assim, a interação homemnatureza e os resultados catastróficos desse contato. Glotfelty (1996) revela que essa abordagem se baseia na asserção de que a cultura humana está associada ao mundo físico, influenciando-o e sendo influenciada por ele. Assim, essa teoria tem como objeto de estudo as conexões entre natureza e cultura, mais precisamente os aspectos culturais que envolvem a linguagem e a literatura. Nesse sentido, a ecocrítica trabalha com o mundo humano e o mundo não humano.

Ecocriticism expands the notion of "the world" to include the entire ecosphere. If we agree with Barry Commoner's first law of ecology, "Everything is connected to everything else" we must conclude that literature does not float above the material world in some aesthetic ether, but, rather, plays a part in an immensely complex global system, in which energy, matter, and ideas interact. (GLOTFELTY, 1996, p. xix) ${ }^{1}$

Se tudo está conectado, a literatura também pode (e deve) contribuir com reflexões acerca do meio ambiente, de modo que seja possível uma reversão dos valores culturais errôneos de superioridade humana e subalternidade da natureza. Além disso, é importante lembrar que a literatura tem buscado imprimir cada vez mais a questão ambiental em suas narrativas, além de expandir os conhecimentos sobre tradições que inviabilizam uma mudança nas práticas antiecológicas.

Em seu caráter multidisciplinar, a ecocrítica tem dialogado de forma particular como os movimentos feministas, dando origem à teoria ecofeminista. Assim, o ecofeminismo surge como uma vertente dos estudos ecocríticos e:

Simboliza síntese do ambientalismo atrelado ao feminismo e propõe que a luta pelos direitos da mulher não seja separada da luta pela reparação dos ecossistemas que sustentam a vida. (TORRES, 2009, p. 174).

\footnotetext{
${ }^{1}$ A ecocrítica expande a noção de "mundo" para incluir toda a ecosfera. Se concordarmos com a primeira lei ecológica de Barry Commoner, "Tudo está ligado a tudo", devemos concluir que a literatura não flutua acima do mundo material em algum éter estético, mas desempenha um papel em um sistema global imensamente complexo, em que energia, matéria e ideias interagem. [Tradução nossa]
} 
Enquanto a ecocrítica se baseia na ideia de que a superioridade humana perante a natureza seja a razão da conduta antiecológica, o ecofeminismo, por sua vez, se baseia na concepção de que existe uma proeminência do homem em relação à mulher, ou seja, da mesma forma que o antropocentrismo seria a causa da exploração desenfreada do meio ambiente, o androcentrismo seria o motivo pelo qual a mulher seria posta em segundo plano na história.

Historicamente, o ecofeminismo é um movimento que surgiu na França, em 1974, idealizado a partir da inquietação gerada pelos efeitos da destruição do meio ambiente, bem como a subjugação das mulheres perante os homens, ambos frutos de uma sociedade patriarcal. A partir daí, acreditava-se que as mulheres seriam de grande ajuda na proteção do meio ambiente, e dar voz a elas - de forma a participarem das grandes decisões sobre como administrar os ecossistemas - seria, de fato, uma possibilidade de solução para os problemas ambientais.

Nesse viés, a teoria ecofeminista se propõe a fomentar importantes discussões em torno das temáticas inerentes aos movimentos ecológicos e das transformações sociais advindas da relação homem-natureza. Segundo a crítica Greta Gaard:

Ecofeminism is a theory that has evolved from various fields of feminist inquiry and activism: peace movements, labor movements, women's health care, and the anti-nuclear, environmental, and animal liberation movements. Drawing on the insights of ecology, feminism, and socialism, ecofeminism's basic premise is that the ideology which authorizes oppressions such as those based on race, class, gender, sexuality, physical abilities, and species is the same ideology which sanctions the oppression of nature. (GAARD et al., 1993, p.03).

Esta teoria contempla uma discussão antiga que não se originou da literatura. No entanto, buscar seus princípios para a análise literária contribui de maneira a enriquecer a reflexão sobre as distopias, haja vista que essas narrativas trazem em si críticas sociais que são, de uma forma ou de outra, exploradas nos movimentos ecofeministas, tais como a opressão das minorias e as discussões ecológicas.

\section{Um olhar sobre umbra (1977)}

\footnotetext{
${ }^{2}$ Ecofeminismo é a teoria que tem envolvido vários campos de investigação e ativismo feminista: movimentos da paz, movimentos relacionados ao trabalho, cuidado e saúde da mulher, e movimentos anti-nucleares, ambientais e liberação de animais. Adentrando na percepção de ecologia, feminismo e socialismo, a premissa básica do ecofeminismo é que a ideologia que autoriza opressões como aquelas baseadas em raça, classe, gênero, sexualidade, habilidades físicas e espécies é a mesma ideologia que sanciona a opressão da natureza. [Tradução nossa]
} 
A começar pelo título, Umbra significa a parte mais escura da sombra, similar à penumbra, o que de forma análoga pode remeter ao período da ditadura no Brasil, considerado, por muitos, como uma fase sombria e nefasta do país, já que torturas, repressão e a não liberdade de expressão eram suas características marcantes.

A obra de Plínio Cabral, inicialmente, descreve uma civilização retraída em um lugar chamado Fábrica. As pessoas que lá viviam dependiam das grandes máquinas para sobreviver; tinham tudo o que precisavam, mas apenas subsistiam. Viviam em cubículos com suas famílias, e nenhuma dessas pessoas foram nomeadas na narrativa. Assim, eram chamados conforme suas características ou função que ocupavam: o menino, o velho, o guarda.

Fora da fábrica, o mundo de Umbra era horrendo, completamente destruído, escuro e poluído. O Velho, um dos personagens da obra, era o único que ia além dos portões da Fábrica, para pescar "mosqueixes" - uma mutação genética que permitiu a união de moscas e peixes - que habitavam o grande mar negro, denominado Marental. Ao sair da fábrica para pescar mosqueixes, o velho arriscava sua vida para exercer o que parecia um ofício propagado de geração em geração. A água do Marental era escura, pesada e consistente demais para que qualquer um pudesse usufruir de seus dotes naturais. $\mathrm{O}$ ar era poluído e pouco amigável, e a terra, por sua vez, não mais produzia frutos.

Ao longo da narrativa, o velho encontra um menino e começa a contar-lhe, em forma de lendas, como chegaram naquela situação deplorável. As narrativas lembram as passagens bíblicas, onde os heróis se assemelhavam a um Messias Salvador. Em uma delas, o Velho menciona a Cidade Morta, que devastava e engolia tudo por onde passava, destruindo principalmente os ecossistemas naturais. Essa cidade representava a grande evolução urbana e tecnológica, que ao invés de melhorar o Planeta, apenas o destruía.

Ao fim da narrativa, o menino decide não herdar os conhecimentos de pesca de mosqueixes do Velho e segue caminho contrário ao da Fábrica, em busca de vida e esperança.

Em Umbra (1977), Cabral faz uma crítica pertinente e necessária que contempla muitas das discussões atuais em torno da relação do homem com a natureza. De maneira velada, mas contundente, o autor faz uma crítica ecológica, utilizando-se de estruturas distópicas para denunciar as ações do homem que reduz os ecossistemas a meros provedores de recursos, sem que haja uma preocupação com o esgotamento destes.

A partir das lendas, o leitor é levado a conhecer um passado que dialoga com o presente, em forma de lembranças. Cada uma delas possui um herói que assume diversos nomes, à medida em que ressuscita na outra Lenda. Eric, Aric, Deric, Teric, Talaric, Taric, Alaric, Laric, Daric, Valderic, Galderic, Genseric, Goderic...são treze lendas, no total. Na primeira delas, o herói, Eric, objetiva matar a Cidade Morta, pois ela devora os habitantes e tudo o que está em sua volta. Ao alcançar o seu objetivo, Eric sucumbe à morte. Assim, os outros que o sucedem têm a missão de salvar os poucos recursos naturais que ainda restam. 
O pássaro, a flor, a água, não resistiam à ação do homem e seu potencial tecnológico. Como a terra estava seca e não havia mais raízes para comer, Genseric conduziu as pessoas até a Cidade Morta, onde construíram a Fábrica em sete anos. No entanto, como todos os outros, muito cansado e já velho, o herói enrolou-se no pó da terra e dormiu. Já Goderic, o único que não desapareceu desta maneira, dissipou-se pelos ares, voando em sua invenção que fazia lembrar o pássaro de Teric.

É pertinente notar que os heróis das lendas apresentam uma relação simbiótica com a natureza, pois já que têm a função de protegê-la, terminam por juntar-se a ela, transformando-se em pó, água ou ar. Ivone Gebara (1997), acerca dessa interdependência, assevera que:

[...] significa acolher como fato básico que uma situação vital, comportamento ou crença é fruto de todas as interações que constituem nossa vida, história, realidade terrena e cósmica mais amplas. Não se trata apenas da interdependência e relação com os outros seres humanos, mas com a natureza, as forças da Terra e do Cosmos. (GEBARA, 1997, p. 61),

Na quarta lenda, intitulada Teric vai à grande mata, e mata, uma vegetação se estendeu a ponto de se tornar uma grande floresta. Contudo, seu tamanho ameaçou os homens da região, que por sua vez decidiram devastá-la gradativamente, como aponta o fragmento a seguir:

Um dia, porém, chegaram os homens e armas, dizendo: 'É preciso vencer a mata' Começou, então, o corte. 'É preciso construir uma estrada', acrescentaram. 'Por ela passarão homens e máquinas'. 'É a civilização’. (CABRAL, 1977, p. 41)

Por meio dessa lenda, é possível verificar o esforço da natureza para sobreviver ao massacre humano em prol da "civilização". A respeito do discurso de progresso, os pesquisadores Gilberto Velho e Eduardo Viveiros de Castro (1978) afirmam:

[...] o fardo do homem branco era educar seus "contemporâneos primitivos", acelerar seu crescimento, que necessariamente iria culminar em um estado idêntico ao já atingido pela civilização do Ocidente. A idéia da civilização, assim, perde seu sentido de processo, e passa a definir um estado - a sociedade ocidental - que deve ser atingido pelos ainda não civilizados. (VELHO; CASTRO, 1978, p. 2-3)

Em outros termos, na sociedade sempre houve as concepções de colonizador e de colonizado, sendo o segundo, na maioria das vezes, visto como inferior e/ou selvagem. Assim, a ideia imperialista de que os outros povos devem se igualar, ao máximo, ao 
exemplo imposto de sociedade evoluída e próspera, é uma das causas das práticas antiecológicas, pois a natureza é oferecida como sacrifício para que se alcance o ideal de civilização supostamente gerado a partir do sentimento de superioridade dos povos opressores. No fragmento a seguir, Cabral convida o leitor a refletir sobre a questão do desmatamento:

E de quando em quando tornava, perguntando: 'E as árvores?' 'Quando plantarão?' E os homens respondiam: 'Amanhã plantaremos. Hoje há trabalho, mil árvores a cortar. Amanhã'. No amanhã Teric, outra vez, perguntava: 'Plantaram?' E eles respondiam: 'Não. Não plantamos. Amanhã plantaremos.' Por fim os homens se irritaram, tomando de suas armas e máquinas contra Teric. Ele, porém, não resistiu. Disse apenas: 'Vocês estão mortos'. (CABRAL, 1977, p. 43)

Considerando o trecho acima, também é possível depreender uma pretensa crítica aos atos praticados durante o Regime Militar no tocante à preservação dos recursos naturais, pois, em nome do progresso, o homem devastava sem nenhum interesse e preocupação com o reflorestamento. Outra causa que justifica tal desapreço é a ideia da supremacia humana, concebida culturalmente quando o homem busca seu lugar como senhor da natureza.

Enquanto distopia, Umbra (1977) revela o lado soturno dessa relação, em que os seres humanos se tornam vilões de si próprios, pois ao destruírem sua fonte de alimento e abrigo, ficarão à mercê de suas próprias invenções imperfeitas e defeituosas, assim como a sociedade resultante dessa relação conturbada. Ainda na quarta lenda, vê-se a personificação da natureza disposta a resistir aos efeitos da modernização e progresso, porém, sem sucesso.

E a Floresta ressurgia além, mais além. E assim andavam - homens e árvores, numa corrida frenética. Atravessaram rios, vales, montanhas, planícies, e chegaram ao mar. A Floresta deteve-se: não podia ir além das grandes águas. Tentou, é verdade. Mas em vão, as raízes mergulhavam na areia salgada, retorcendo-se, dolorida. (CABRAL, 1977, p. 41)

Nessa perspectiva, Christopher Manes, em Nature and Silence (1996), discorre sobre a voz da natureza evidente mediante vários sons, dentre eles o barulho dos animais, o som da água dos rios e o ruído dos ventos, que por não serem como a fala dom exclusivo do ser humano - silenciam, tornam-se explorados e, por vezes, marginalizados.

Christopher Manes (1996) também faz uma comparação entre as sociedades "civilizadas" e as animistas (aquelas que se baseiam na crença de que existe alma em todas as coisas da natureza). Essas comunidades, em razão de tal peculiaridade, percebem uma voz nos animais, nas águas, nas árvores e acreditam que esses seres, 
inclusive os inertes, como as pedras, podem interagir e possuir sentimentos, além de ter uma linguagem inteligível e aceitável.

Reflexão semelhante pode ser percebida na obra $O$ caçador de Androides (1968), de Philip K. Dick, autor norte-americano notável por suas obras de ficção científica, capazes de levar o leitor a refletir sobre temas que provocam questionamentos e inquietações, tais como os problemas ecológicos, como veremos a seguir.

\section{Um olharsobre O caçador de Androides (1968)}

O caçador de Androides (1968) narra a história do planeta Terra pós-apocalíptico. A grande evolução tecnológica produziu armas nucleares tão potentes a ponto de eliminar boa parte dos animais, deformar genes humanos, assassinar a maioria deles e expulsar uma pequena parte da população terráquea (para viver em uma colônia em Marte). A Guerra Mundial Terminus já havia acabado, mas a poeira nuclear estava impregnada no ar, fazendo os seres humanos viverem à mercê dela.

Essa poeira danosa e maléfica forçava a maior parte da população a migrar para Marte, onde eram presenteados com androides de última geração para bem servi-los no planeta estranho. Rick Deckard, o caçador de androides, trabalhava a fim de conseguir recompensas em dinheiro para, então, realizar seu sonho de ter um animal de estimação de verdade (que eram bastante caros, já que estavam praticamente em extinção). Rick possui uma companheira em casa, Iran, sua esposa, uma humana que contribui com diálogos interessantes com o marido, e Rachael Rosen, sua companheira de missão e mulher androide.

Rick Deckard tem uma profissão um tanto peculiar: é um "caçador de androides", cuja missão é "aposentar" os últimos androides modelo Nexus-6, que são os mais perfeitos já criados e altamente semelhantes aos espécimes humanos. Isso faz com que aposentá-los não se torne uma tarefa fácil, já que eliminar um ser humano por acidente implicaria em uma grande punição.

Iran, a esposa, não aprova a profissão do marido, pois sente pena dos androides "mortos" por Rick. Ela é uma mulher aparentemente deprimida e angustiada; pouco entusiasmada com o mundo em que vive. Assemelha-se a um viciado em drogas, ao se conectar ao aparelho condicionador de emoções frequentemente. Assim, ela se mantém em uma vida superficial e pessimista.

Por outro lado, Deckard sonha em ganhar a tal recompensa para adquirir um animal de estimação. Os animais protegidos por humanos em suas casas representavam status social, pois eram muito caros, razão pela qual nem todas as pessoas poderiam comprá-los. Apesar da crítica da esposa em relação à sua profissão, Deckard se engaja em uma missão bastante perigosa, pondo até mesmo a sua vida em risco.

Ao longo da história, sempre é posto em destaque o caos ao redor do mundo. $\mathrm{O}$ planeta Terra havia se tornado uma ameaça para a saúde humana, pois muitos haviam morrido em decorrência da Grande Guerra Mundial Terminus, e milhares ainda iriam morrer por causa de uma poeira radioativa resultante da guerra. Para alguns, não havia 
mais saída, pois nem mesmo eram considerados mais humanos, para outros, ficar na Terra significaria simplesmente permanecer em seu lar, apesar de todo o caos instalado.

$O$ caçador de androides (1968) apresenta um mundo futurista e tecnologicamente desenvolvido. As pessoas possuem máquinas que controlam suas emoções, sendo possível programá-las para terem diversas sensações. Em uma discussão entre Rick e a esposa Iran, é mencionada uma dessas máquinas, o órgão condicionador Penfield, que através da discagem de códigos estimula humanos a terem diferentes sensações. No contexto da discussão, Iran comenta ter discado um código que a faz ficar depressiva por quase um dia inteiro, já que ela se sentiu muito incomodada com o fato de ter sido indiferente ao edifício vazio, pois muitas pessoas ou morreram, ou se mudaram para Marte, dada a situação deplorável do planeta Terra.

\begin{abstract}
Deixara que essa informação permanecesse num segundo plano; como a maioria das pessoas, não queria verificá-la diretamente - Naquele momento - continuou Iran -, quando desliguei o som da TV, eu estava num estado de espírito 382. Acabava justamente de discar isso. De modo que, embora intelectualmente eu ouvisse o vazio, não o sentia. Minha primeira reação foi de agradecimento, porque a gente podia comprar um órgão condicionador Penfield, mas depois, compreendi como isso era doentio, sentir a ausência de vida, não só neste prédio, mas em toda parte, e não reagir, compreende? Acho que não. Mas isso era, antes, considerado como sintoma de doença mental, chamavam a isso de "ausência do afeto apropriado". (DICK, 1968, p. 5-6)
\end{abstract}

Nessa passagem, observa-se que, realmente, deve ser difícil para qualquer pessoa diferenciar humanos de androides, já que os próprios seres humanos não se sentem como humanos, pois precisam de uma máquina que regule suas emoções. Ao experimentar a "ausência humana", Iran se sentiu angustiada, pois não sabia mais como era sentir solidão e todos os sentimentos negativos que perpassam por um ser normal. Então, ela resolveu que, ainda que por meio do aparelho, deveria se sentir deprimida diante do mundo em que vivia, por menor que fosse esse sentimento.

Na perspectiva do ecofeminismo, as mulheres possuem uma sensibilidade maior para com a natureza, por isso são próximas a ela. Essa similaridade, algumas vezes, atribui um caráter de inferioridade para o sexo feminino, pois, assim como a natureza, a mulher pode ser considerada um ser selvagem e menos "racional". No entanto, por uma perspectiva mais otimista, a sensibilidade interpretada como uma característica inferior pode vir a ser uma ferramenta de mudança. Nesse sentido, a ecofeminista Judith Plants (1997), salienta que "It's true that women have been socialized in a way that allows them to experience compassion ${ }^{3}$ " (PLANTS, 1997, p.130), possibilitando assim maior engajamento e reatividade com os problemas ecológicos.

Na obra de Dick, Iran resolveu, por um momento, refletir sobre a situação terrível de seu planeta e, ao contrário de Rick, ela não queria se distanciar de sua "humanidade", ${ }^{3}$ É verdade que as mulheres foram socializadas de uma forma que lhes permite experimentar a
compaixão. [Tradução Nossa] 
mesmo que para isso sacrificasse sua satisfação emocional, artificialmente construída através da tecnologia. $O$ trecho a seguir demonstra essa reflexão mais profunda que a personagem teve a esse respeito:

\begin{abstract}
Assim, deixei desligado o som da TV, sentei-me ao meu órgão e fiz uns experimentos. Finalmente, descobri uma combinação para desespero. Seu rosto moreno, animado, mostrou satisfação, como se ela houvesse realizado alguma coisa de valor. - De modo que coloquei isso em minha programação duas vezes por mês. Acho que é um período razoável de tempo para a gente se sentir impotente a respeito de tudo, de ficar aqui na Terra, depois que toda a gente sabida emigrou. (DICK, 1968, p. 6)
\end{abstract}

Ficar na Terra poderia significar a morte, em razão da poeira nuclear que se espalhava no ar e ia matando as pessoas aos poucos ou as deformando, a ponto de não serem mais consideradas humanas, ou "úteis", já que não podiam mais procriar e dar continuidade à civilização humana. Tem-se aqui uma clara referência não somente à morte física, mas também à morte social.

O legado da guerra mundial terminus perdera algo de sua potência; os que não puderam sobreviver à poeira estavam mortos há muito tempo e ela, mais fraca agora e enfrentando sobreviventes mais fortes, apenas desequilibrava mentes e propriedades genéticas. (DICK, 1968, p. 8)

As guerras têm o poder de devastar não apenas o ambiente físico, mas tudo aquilo que está de uma forma ou de outra vinculado a esse ambiente: história, memórias, cultura. Assim, as distopias podem ter um caráter, por vezes, profético ao apresentarem os problemas do presente e os possíveis resultados catastróficos que eles possam gerar. Esses efeitos marcam também as relações pessoais que se mostram superficiais ou inexistentes. Na citação a seguir, notamos a prepotência de Rick ao se dirigir à esposa:

Muito bem, desisto. Vou discar. Tudo o que você quiser que eu faça, felicidade sexual extática... Eu me sinto tão mal que suporto mesmo isso. Droga. Que diferença isso faz?

- Eu disco para nós dois - ofereceu-se Rick e levou-a para o quarto. Ao consolo da esposa, discou 594, o satisfeito reconhecimento da sabedoria superior do marido em todas as coisas. (DICK, 1968, p. 7)

Após uma longa discussão com o marido, Iran acaba por ser vencida pela insistência dele em decidir por ela, até mesmo em controlar suas emoções. Vê-se aqui uma referência explícita aos costumes patriarcais em que o marido é o guardião e provedor da esposa, e, portanto, sente-se no direito de persuadi-la a fazer sua vontade. 
Assim, em um mundo caótico e superficial, onde quase não há mais vida natural, aplicase a premissa do ecofeminismo em que:

[...] the ideology which authorizes oppressions such as those based on race, class, gender, sexuality, physical abilities, and species is the same ideology which sanctions the oppression of nature. ${ }^{4}$ (GAARD et al., 1993, p. 1)

Na obra de Philip K. Dick, são perceptíveis as condições deploráveis em que se encontram os recursos naturais. Em prol do progresso, a dualidade entre homem e natureza é justificada e se mantém através da ideologia de opressão e do domínio absoluto dos que são subjugados.

Como forma de resistência, o autor traz à baila mais uma figura feminina, Rachael Rosen, classificada como uma androide Nexus-6, isto é, uma robô construída para se parecer infinitamente igual a um ser humano. Mesmo em um suposto futuro evoluído, as mulheres continuam sem ter a liberdade de decidir sobre muitas coisas, como, por exemplo, seu próprio corpo.

- Você é engravidada - continuou Rick - por um homem que prometeu casar com você. O homem vai embora com outra mulher, sua melhor amiga. Você faz um aborto e...

- Eu nunca faria um aborto - retrucou Rachael - De qualquer modo, não posso. Significa prisão perpétua e a polícia anda sempre vigilante. Desta vez, ambos os ponteiros saltaram violentos para o vermelho. (DICK, 1968, p. 30)

No romance de Philip K. Dick, nota-se uma discussão atual e pertinente que comunga com muitas vertentes do movimento feminista, incluindo a pauta da liberdade de escolha da mulher de ser mãe ou não. Tolher a liberdade das mulheres aparenta ser um aspecto marcante nesta sociedade que vive de ruínas, tecnologia avançada e quase nenhuma liberdade. Isso demonstra que a sociedade representada na obra de Dick é orientada pelo patriarcalismo, em que os homens possuem direito a tudo, enquanto as mulheres, não. Acerca dessa desigualdade, as pesquisadoras Lorena Lúcia Monteiro e Lívia Freire Silva trazem à tona questões relacionadas às divisões de trabalho:

\footnotetext{
${ }^{4}[\ldots .$.$] a ideologia que autoriza opressões como aquelas baseadas em raça, classe, gênero,$ sexualidade, habilidades físicas e espécies é a mesma ideologia que sanciona a opressão da natureza. [Tradução nossa]
} 
Engels e Marx se referem à relação homem/mulher como a primeira divisão do trabalho já feita, a primeira opressão de classes, com a opressão do sexo feminino pelo masculino. Diz ainda que esse período dura até nossos dias [...] (MONTEIRO; SILVA, 2018, p. 3)

É problemática a percepção de que esse primeiro princípio de opressão do ser feminino ainda perdure. Mesmo considerando que muitas mudanças já aconteceram através da luta das mulheres por seus direitos, ainda há muito o que se refletir e discutir para converter essas divisões de trabalho em condições igualitárias.

Outro ponto a ser destacado na obra, que se adequa à teoria ecofeminista, é a exploração dos animais. Os animais fazem parte da dominação humana e, assim como as mulheres, pertencem a uma categoria inferior na lógica patriarcal e, sobretudo, capitalista.

A população que permanece no planeta vive enclausurada em cidades decadentes e vazias, envenenada pela radiação que danifica seus genes. A maioria dos animais foi extinta e possuir um deles é uma prova distinta da empatia humana, mas principalmente é um símbolo de status. Quanto mais raro o animal, maior o status do proprietário. Pessoas que não podem pagar por um animal de verdade compram animais sintéticos. (DICK, 1968, p. 2)

Percebe-se que a extinção animal se deu pela radiação produzida nas guerras. Consequentemente, a comercialização dos poucos animais que restaram gerou uma obsessão por parte da população que detinha maior poder aquisitivo. Os animais eram vendidos em um catálogo e vistos como objetos de grande valor, pois quanto mais animais uma pessoa possuía, mais status poderia ter. Sobre isso, Monteiro e Silva discorrem:

\begin{abstract}
A crueldade com os animais é algo percebível dentro das relações sociais na sociedade nativa e na nossa. A base econômica de nossa sociedade é de exploração, seja ela de indivíduo para indivíduo, como ocorreu no Brasil como colônia de extração, até os dias de hoje, ou a exploração animal. As relações de exploração não permanecem estagnadas, sempre têm que ser revigoradas de alguma forma, o capitalismo tem que se adequar para suprir as necessidades humanas. O que se pretende dizer aqui, é até onde essas necessidades são usadas como ética e respeito aos demais. (MONTEIRO; SILVA, 2018, p. o1)
\end{abstract}

O planeta Terra do futuro descrito por Philip K. Dick é um lugar onde as pessoas se tornam cada vez mais solitárias, vivendo em redes sociais virtuais sem nenhuma interação real. A tecnologia é renovada todos os dias, graças às fábricas que poluem o ar e os rios, tornando a vida natural cada vez mais insustentável. 


\section{Considerações finais}

Em termos gerais, é significativo e pertinente o diálogo entre a literatura e as teorias ecofeminista e ecocrítica, pois isso viabiliza uma reflexão mais ampla sobre aspectos sociais da vida humana que necessitam de ponderação. A função da literatura, além de tantas outras, é instigar e gerar reflexões sobre os problemas sociais, sendo estes o principal alvo das distopias. Portanto, estabelecer conexões entre o ecofeminismo, a ecocrítica e as distopias pode motivar a ocorrência de muitos debates e discussões frutíferas no meio acadêmico.

As obras analisadas neste estudo possibilitam elucubrações atuais que dialogam com as discussões levantadas não apenas no ambiente acadêmico, mas também no meio político e econômico, haja vista seu caráter interdisciplinar e universal. Portanto, tratar das transformações e mudanças sociais oriundas do processo de modernização tecnológica requer uma visão ampliada da relação entre homem e ambiente, o que nos faz ver na literatura uma vertente propícia para observações de caráter social, pois ainda que seja subjetiva e ficcional, retrata a realidade e, desse modo, provoca questionamentos, e por vezes, desconforto e inquietações.

Estudar literatura, destarte, enriquece o conhecimento humano e, academicamente, abre caminhos para novas teorias, já que novos conhecimentos, ainda que imbuídos de subjetividade, em algum momento produzem ações concretas e efetivas em prol do bem-estar da sociedade.

\section{Referências}

CABRAL, Plínio. Umbra. São Paulo: Summus Editorial, 1977.

DICK, Philip K. O caçador de Androides.São Paulo: Aleph, 1968.

GAARD, Greta et al (Ed.). Ecofeminism: women, animals, nature. Filadélfia: Temple University Press, 1993. 
GEBARA, Ivone. Teologia Ecofeminista: "Ensaio para repensar o Conhecimento e a Religião”. São Leopoldo: Olho D'água, 1997.

GLOTFELTY, Cheryll; FROMM, Harold (Ed.). The Ecocriticism Reader: Landmarks in Literary Ecology. Athens: University Of Georgia Press, 1996.

MANES, Christopher. Nature and Silence. In: GLOTFELTY, Cheryll; FROMM, Harold. The Ecocriticism Reader:Landmarks in Literary Ecology. Athens: University Of Georgia Press, 1996.

MONTEIRO, Lorena Lúcia C.; SILVA, Lívia Freire da. Ecofeminismo e abolição animal: quebra da lógica patriarcal por um novo paradigma.

Disponível em: <http://www.abolicionismoanimal.org.br/artigos.php?cod=16>. Acesso em: 06 ago. 2018.

PLANTS, Judith. Learning to live with differences. In: WARREN, Karen J. Ecofeminism: women, Culture, Nature. Indianopolis: Indiana University Press, 1997.

TORRES, Maximiliano. O ecofeminismo: "Um termo novo para um saber antigo". Rio de Janeiro, Terceira Margem, v. 1, n. 20, p. 157-175, jun. 2009.

VELHO, Gilberto; VIVEIROS DE CASTRO, Eduardo. O Conceito de Cultura e o Estudo das Sociedades Complexas: uma perspectiva antropológica. Artefato: Jornal de Cultura. Rio de Janeiro: Conselho Estadual de Cultura, n. 1, jan. 1978.

*Professora do programa de Pós-graduação em Letras da Universidade Federal do Maranhão. ${ }^{* *}$ Mestra em Letras pela Universidade Federal do Maranhão e professora de Língua e Literatura Inglesa. 